09.6

\title{
Высокочастотные рельефно-фазовые голографические решетки на обработанном коротковолновым УФ-излучением бихромированном желатине
}

\author{
(C) Н.М. Ганжерли ${ }^{1}$, С.Н. Гуляев ${ }^{2}$, И.А. Маурер ${ }^{1}$, Д.Р. Хазвалиева ${ }^{2}$ \\ ${ }^{1}$ Физико-технический институт им. А.Ф. Иоффре РАН, Санкт-Петербург, Россия \\ ${ }^{2}$ Санкт-Петербургский государственный политехнический университет Петра Великого, Санкт-Петербург, Россия \\ E-mail: nina.holo@mail.ioffe.ru
}

Поступило в Редакцию 15 марта 2019 г.

В окончательной редакции 15 марта 2019 г.

Принято к публикации 26 марта 2019 г.

Впервые показана возможность создания рельефно-фазовых голографических решеток с высокой пространственной частотой $1500 \mathrm{~mm}^{-1}$ на слоях бихромированного желатина при использовании деструктивного воздействия коротковолнового УФ-излучения на желатин.

Ключевые слова: голографические дифракционные решетки, поверхностный рельеф, коротковолновое УФ-излучение, бихромированный желатин.

DOI: 10.21883/PJTF.2019.12.47915.17787

Для преобразования амплитудной голографической записи в рельефно-фазовую на галоидосеребряных фотоматериалах ранее был разработан эффективный метод, базирующийся на деструктивном воздействии на желатин коротковолнового УФ-излучения [1]. Впоследствии этот метод был применен к слоям бихромированного желатина (БХЖ) для создания низкочастотных дифракционных решеток с частотой $v$ порядка $100-200 \mathrm{~mm}^{-1}$ и высотой поверхностного рельефа $h$ около $1 \mu \mathrm{m}[2,3]$.

Однако современные оптические технологии используют дифракционные решетки с более высокой пространственной частотой $v$ : от $1000 \mathrm{~mm}^{-1}$ до субволнового диапазона. Такие решетки широко применяются в спектральных приборах, а также в телекоммуникационных системах и лазерной технике в качестве дифракционных оптических элементов, антиотражающих поверхностей, модуляторов, оптических датчиков линейных и угловых перемещений, фильтров, поляризационных элементов, светоделителей и т. д. [4-6].

При голографической записи интерференционной картины на БХЖ излучением $\mathrm{He}-\mathrm{Cd}$-лазера изменение физико-химических свойств желатина осуществляется непосредственно вследствие избирательного светового дубления регистрирующим лазерным излучением в присутствии бихроматов. При этом происходит структурирование, т.е. установление большого количества поперечных связей в максимумах интерференционной картины (рис. $1, a)$.

Первичная обработка образцов после экспонирования решеток $\mathrm{He}-\mathrm{Cd}$-лазером, заключающаяся в „купании“ в воде и сушке, приводит к появлению рельефа высотой $h$ порядка $0.1 \mu \mathrm{m}$, который в соответствии с приведенным ранее критерием создания эффективных голографических решеток [7] будет недостаточен для получения высоких значений дифракционной эффектив- ности (ДЭ). На следующих стадиях обработки образцов (рис. $1, a)$ участки слоя с желатином, подвергнутые световому дублению лазерным излучением, менее поддаются разрушающему воздействию коротковолнового УФ-излучения, поскольку большое количество поперечных связей препятствует фрагментации желатиновых макромолекул и растворению их в воде. Таким образом, горбы поверхностного рельефа на слое БХЖ после воздействия УФ-света и водной процедуры образуются в максимумах интерференционной картины.

Ранее было получено [8], что содержащие желатин регистрирующие среды для голографии, обработка которых включает продолжительное пребывание в водных растворах, независимо от методов получения рельефнофазовых структур имеют ограничения по передаче пространственно-частотного спектра в области высоких частот $v \geq 200 \mathrm{~mm}^{-1}$. Спад высоты $h$ поверхностного рельефа или связанной с ним ДЭ может быть теоретически объяснен сглаживающим воздействием сил поверхностного натяжения, возникающих во влажном желатиновом слое, роль которых существенно возрастает на высоких пространственных частотах [8,9]. Продолжительное „купание“ образцов в воде в течение нескольких минут после засветки УФ-излучением по используемой нами стандартной методике обработки слоев [2,3] приводит к набуханию слоя БХЖ по всей толщине (рис. 1,a). Поэтому мягкий податливый желатин легко деформируется под действием сил поверхностного натяжения, в результате чего при окончательной сушке на воздухе происходит сглаживание поверхностного рельефа на высоких частотах $[8,9]$.

Задача настоящей работы состоит в уменьшении влияния сил поверхностного натяжения для получения значительной высоты поверхностного рельефа. Для этого нами было предложено существенно сократить время 


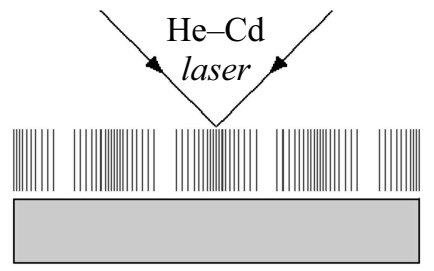
a
Exposure of DCG layer
to He-Cd laser radiation

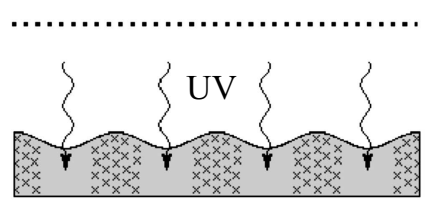

DCG layer treatment

Exposure of dried

DCG layer

to UV radiation

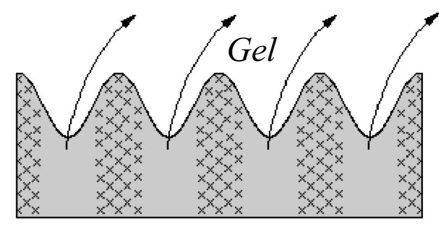

Washing, removal of irradiated degraded gelatin

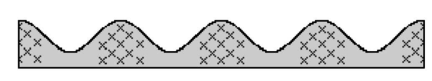

Final air drying

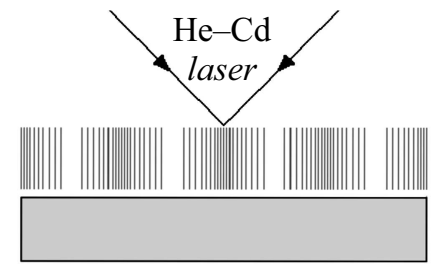

$b$

Exposure of DCG layer to $\mathrm{He}-\mathrm{Cd}$ laser radiation

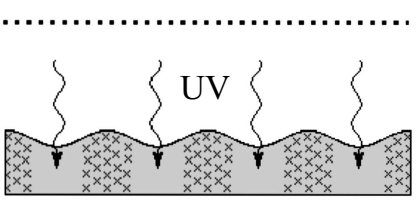

DCG layer treatment

Exposure of dried

DCG layer

to UV radiation

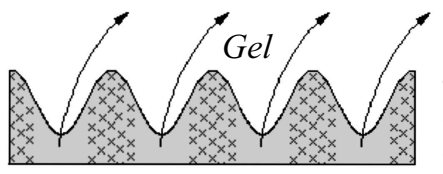

Short term washing, removal of irradiated degraded gelatin

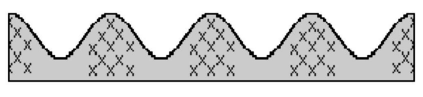

Fast dehydration with isopropanol

Рис. 1. Этапы получения поверхностного рельефа на слоях БХЖ на высоких пространственных частотах. $a-$ стандартная методика обработки, $b$ - предложенная методика.
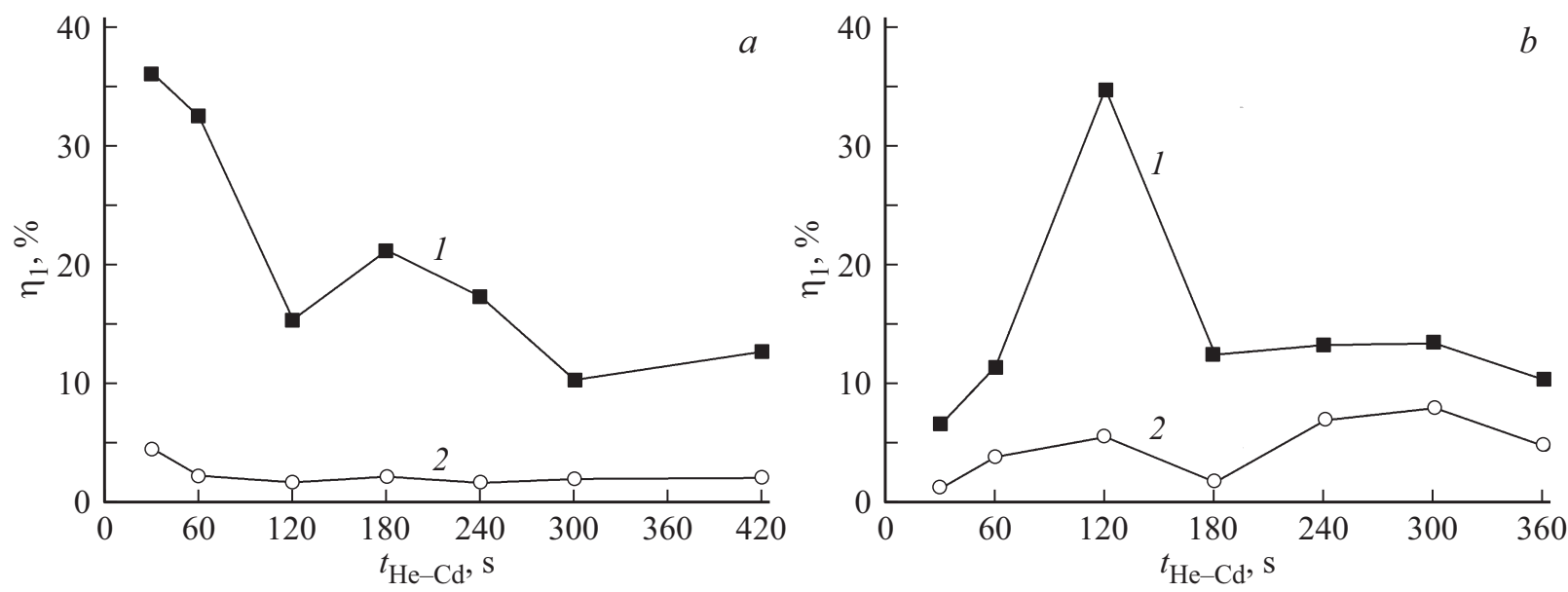

Рис. 2. Зависимость ДЭ $\eta_{1}$ решеток при оптимальном угле падения луча лазера на образец со стороны желатинового слоя от времени экспонирования голограмм Не-Сd-лазером. $a-$ с использованием УФ-излучения при обработке слоя толщиной $4.9 \mu \mathrm{m}(1)$ и без использования УФ-излучения (2); $b$ - для слоя толщиной $5.1 \mu \mathrm{m}$ с открытой поверхностью решетки $(1)$ и для поверхности решетки с нанесенной иммерсионной жидкостью (2).

„купания“ образцов в воде после УФ-облучения. В этом случае разрушенные ультрафиолетом участки желатина успевают раствориться в воде быстрее, чем набухнут внутренние слои желатина. Для предотвращения набухания слоя желатина по толщине нами также было предложено использование ванны с изопропиловым спиртом непосредственно после короткой водной обработки (рис. $1, b)$. При этом в образовании голографической структуры участвует только поверхностный слой желатина, а действие сил поверхностного натяжения минимизировано. Предложенная методика по сравнению со стандартной должна привести к существенному увеличению высоты поверхностного рельефа на высоких пространственных частотах.

Слои БХЖ изготавливались в лабораторных условиях подобно известному способу, описанному в работе [10]. Запись голографических решеток с пространственной частотой $v=1500 \mathrm{~mm}^{-1}$ осуществлялась по симметричной оптической схеме излучением $\mathrm{He}-\mathrm{Cd}$-лазера с длиной волны $440 \mathrm{~nm}$. После экспонирования сухого слоя БХЖ образцы решеток обрабатывались „купанием“ в 2\% растворе сульфита натрия в течение 6 min для 


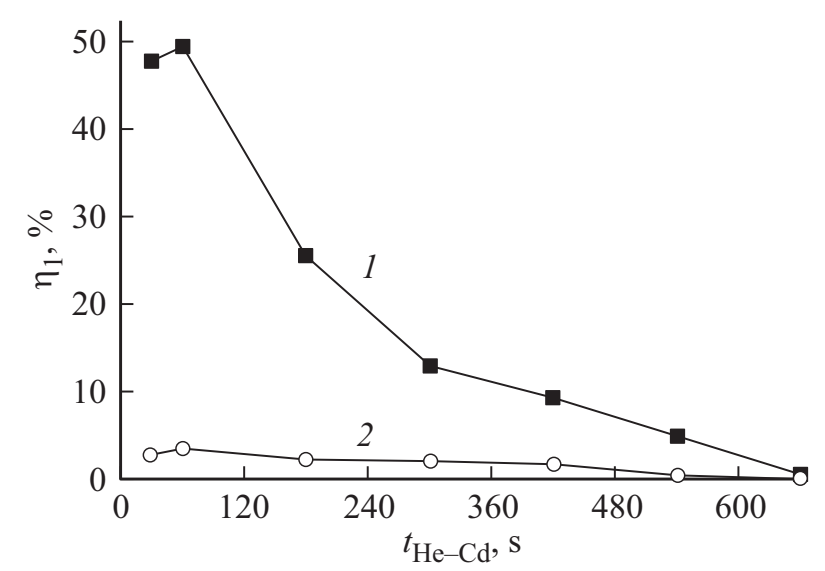

Рис. 3. Зависимость ДЭ $\eta_{1}$ решеток при оптимальном угле падения луча лазера на образец толщиной $T=0.7 \mu \mathrm{m}$ со стороны желатинового слоя от времени экспонирования голограмм $\mathrm{He}-\mathrm{Cd}$-лазером. 1 - без использования иммерсии, 2 - с использованием иммерсии.

завершения процессов дубления желатина и удаления соединений хрома из слоя. Далее промытые в воде и высушенные образцы решеток засвечивались УФ-излучением с помощью ртутно-кварцевой лампы высокого давления ДРТ-220 в течение 20-24 min. Затем образцы обрабатывались в течение $10 \mathrm{~s}$ в воде и немедленно погружались в чистый изопропиловый спирт последовательно в две ванны (по $1 \mathrm{~min}$ в каждой) для быстрого обезвоживания слоя.

Измерение ДЭ решеток проводилось при считывании лучом $\mathrm{He}-\mathrm{Ne}$-лазера с длиной волны $630 \mathrm{~nm}$ при оптимальном угле падения на образец со стороны желатинового слоя. На рис. 2, a (кривая 1) приведена зависимость ДЭ в первом порядке дифракции от времени $t_{\mathrm{He}-\mathrm{Cd}}$ экспонирования решеток $\mathrm{He}-\mathrm{Cd}$-лазером. Толщина слоя БХЖ для данного образца вне области решетки составляла $T=4.9 \mu \mathrm{m}$. Достигнутая максимальная ДЭ, равная $35 \%$, многократно превышает эту величину (1.73\%) для образцов решеток той же пространственной частоты, обработанных после засветки ультрафиолетом по ранее использованной стандартной методике [2,3]. Кривая 2 на рис. 2,a отражает ДЭ участков того же образца, не облученных УФ-излучением. Сравнение кривых 1 и 2 указывает на существенную роль деструктивного воздействия УФ-излучения в формировании поверхностного рельефа за счет удаления водой разрушенных УФизлучением молекул желатина.

Факт наличия эффективной рельефной решетки подтверждается экспериментами с применением иммерсионной жидкости. На рис. 2, $b$ показана зависимость ДЭ от времени экспозиции когерентным излучением лазера $t_{\mathrm{He}-\mathrm{Cd}}$ для голографических решеток с открытой поверхностью (кривая 1) и с поверхностью с нанесенной иммерсионной жидкостью, покрытой покровным стеклом (кривая 2). Толщина слоя БХЖ в данном случае составляла $5.1 \mu \mathrm{m}$. В качестве иммерсионной жидкости использовалось масло, показатель преломления которо- го приблизительно равнялся показателю преломления желатина. Представленные на рис. 2, $b$ зависимости свидетельствуют о преимущественно рельефном механизме дифракции.

Максимальная ДЭ для решеток, зарегистрированных на слоях БХЖ толщиной порядка $5 \mu \mathrm{m}$, в наших экспериментах доходила до величин 40-45\%. При понижении толщины слоев БХЖ до величины 0.5-0.7 $\mu \mathrm{m}$ экспериментально зарегистрированы максимальные значения ДЭ 41-50\% (рис. 3). Высокие значения ДЭ для решеток, полученных на сверхтонких слоях БХЖ, являются дополнительным аргументом в пользу существования эффективной рельефной поверхностной структуры.

В работе показана эффективность усовершенствованной методики обработки голографических структур на слоях БХЖ, которая осуществляется после деструктивного воздействия коротковолновым УФ-излучением на желатин. Это позволило впервые получить на БХЖ рельефные голографические решетки с высокой пространственной частотой $v=1500 \mathrm{~mm}^{-1}$ и максимальной ДЭ порядка 50\%, превышающей значения дифракционной эффективности для полученных ранее низкочастотных голографических решеток [3].

В заключение отметим, что результаты работы будут способствовать расширению сферы применения рельефных голографических решеток, регистрируемых на такой широко распространенной и обладающей высокими оптическими параметрами среде, как слои БХЖ.

\section{Конфликт интересов}

Авторы заявляют, что у них нет конфликта интересов.

\section{Список литературы}

[1] Гуляев С.Н., Ратушный В.П. // Опт. журн. 2003. Т. 70. № 2. C. 45-49. DOI: 10.1364/JOT.70.000105

[2] Ганжерли Н.М., Гуляев С.Н., Маурер И.А. // Письма в ЖТФ. 2016. Т. 42. В. 19. С. 26-30. DOI: $10.1134 / \mathrm{S} 1063785016100060$

[3] Ганжерли Н.М., Гуляев С.Н., Маурер И.А. // Опт. журн. 2017. T. 84. № 9. C. 1-5. DOI: 10.1364/JOT.84.000617

[4] Popov E. Introduction to diffraction gratings: summary of applications // Theory and numeric applications. Marseille: Presses Universitaires de Provence (PUP), 2012. P. 1.1-1.23. www.fresnel.fr/numerical-grating-book

[5] Bondos N., Neauport J. // Adv. Opt. Photon. 2016. V. 8. N 1. P. 1-44. dx.doi.org/10.1364/AOP.99.099999

[6] Diffraction gratings. Mechanically ruled or holographically recorded.

https://www.zeiss.com/spectroscopy/products/gratings.html

[7] Calixto S., Ganzherli N., Gulyaev S., Figueroa-Gerstenmaier S. // Molecules. 2018. V. 23. N 8. P. 2064-2086. DOI: $10.3390 /$ molecules 23082064

[8] Гуляев С.Н. // Научно-технические ведомости СПбГПУ. Основной выпуск. 2008. № 3 (59). С. 105-114.

[9] Бутусов М.М., Иофбе А.И. // Квантовая электроника. 1976. T. 3. № 5. C. 969-974.

[10] Shankoff T.A. // Appl. Opt. 1968. V. 7. N 10. P. 2101-2105. DOI: 10.1364/AO.7.002101 